\title{
Os SENTIDOS DO \\ Discurso Político DE JK
}

\author{
Joana D'Arc Moreira Nolli \\ Ana Cleide C. Cesário 2
}

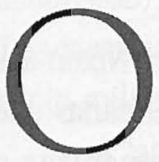

presente artigo visa a compreensão da ideologia desenvolvimentista no período de Juscelino Kubitschek. Como instrumento de interpretação, será utilizada a análise de discurso, fundada por Michel Pêcheux. 0 discurso "Exposição do Presidente da República às Forças Armadas" proferido por JK em 17 de junho de 1958 é o objeto de investigação deste trabalho e o par desenvolvimento/segurança 0 orientador da análise. Este discurso diz respeito à política externa de JK e se refere à Operação Pan-Americana/OPA.

Segundo Moura, a OPA foi uma idéia que saiu do Palácio do Catete no Rio de Janeiro em maio de 1958 para as mãos do Presidente dos Estados Unidos, Dwight Eisenhower, e que possuía os seguintes objetivos: assegurar as boas relações com a superpotência americana que deveriaser, em última análise, a fonte de recursos para esse ambicioso projeto; captar recursos em vasta escalapara projetos de desenvolvimento econômico e; colocar o Brasil numa posição de liderança entre os países latino-americanos. ${ }^{3}$

Os argumentos de JK, tanto na política interna como na externa, sobre a sua preocupação em desenvolver a América Latina envolviam a Guerra Fria, conflito que se originou das desavenças entre EUA e URSS durante a Segunda Guerra Mundial e que adquiriu caráter de conflito permanente a partir de 1947 quando as diferenças entre os dois países, que emergiram da guerra não apenas como os grandes vencedores, mas também como duas superpotências mundiais, se exacerbaram. Tratava-se principalmente de um conflito de natureza estratégico-militar, mas que se revestia também de aspectos econômicos e político-ideológicos, dividindo o mundo em dois grandes blocos: de um

\footnotetext{
1 Mestranda em Ciências Sociais na Universidade Estadual de Londrina.

2 Professora Titular de Ciência Política do Depto. de Ciências Sociais/UEL.

3 MourA, G. Avanços e recuos: a política exterior de JK. In: Castro GoMes, A.M. (ORG.). O Brasil de JK. Rio de Janeiro: Editora FGV, 2002. p. 51.
} 
lado, um bloco capitalista, cujo modelo de organização política tendia a ser a democracia de cunho liberal, e, de outro, um bloco socialista, cuja organização político-social reproduzia, em maior ou menor medida, o socialismo planificado vigente na URSS.

0 Brasil eraparte do bloco ocidental, do denominado Terceiro Mundo emergente e, apesar de a América Latina se inserir plenamente como "zona de influência" dos EUA, desde o final da Segunda Guerra Mundial, o relacionamento entre a superpotência e seus aliados hemisféricos vinha sendo marcado por crescentes divergências, principalmente no terreno econômico, uma vez que os países latino-americanos se encontravam assolados por problemas econômicos crônicos e precisavam de recursos para superar sua condição de subdesenvolvimento. ${ }^{4}$

Em 1958, numa visita do vice-presidente norte-americano Richard Nixon aos países da América Latina, ocorreram manifestações populares antiamericanas que expressavam 0 descontentamento com a falta de recursos para amenizar 0 subdesenvolvimento. JK, aproveitando-se das circunstâncias, enviou uma carta ao presidente americano Eisenhower lamentando 0 grau de deterioração das relações hemisféricas e propôs uma revisão do pan-americanismo. Nasce assim a OPA e com ela, uma nova definição para a segurança e para o desenvolvimento.

0 conceito de segurança seria ampliado para além da defesa militar da nação, das questões de fronteira e ameaças de guerra e também passaria a estar relacionado ao desenvolvimento da América Latina. Ademocracia Ocidental dependia do desenvolvimento dos países pobres, ou seja, a segurança teria como base de sustentação o desenvolvimento. Esta foi a estratégia que JK colocou em prática para tentar convencer os EUA quanto a necessidade de investir recursos para a superação do subdesenvolvimento, uma vez que a hostilidade americana aos planos de desenvolvimento nacional era evidente e que nem mesmo com o Programa de Metas eles se entusiasmaram. Conforme destaca Benevides, eles estavam muito mais preocupados com o combate à "subversão comunista" do que com 0 desenvolvimento latino-americano. ${ }^{5}$ Aliar desenvolvimento à segurança foi a opção que melhor se adequou ao contexto.

Quanto às Forças Armadas, 0 importante para JK era conseguir o comprometimento dos militares com o desenvolvimento econômico.JK reconhecia que não conseguiria governar sem um aparato militar bem estruturado e reconhecia também

4 Para uma compreensão mais aprofundada sobre a Guerra Fria e a relação do Brasil com os EUA nesse período ver VIzENTINI, P. F. Relações exteriores do Brasil (1945-1964): o nacionalismo e a política externa independente. Petrópolis: Vozes, 2004.

5 BEnevides, M. V. O governo Kubitschek: o desenvolvimento econômico e estabilidade política, 1956-1961. Rio de Janeiro: Paz e Terra, 1979. p. 237. 
que a manutenção da ordem política no Brasil dependia desta instituição. Mas a questão da luta contra o subdesenvolvimento na América Latina implicava na segurança do continente, o que acarretaria ligação política com os Estados Unidos para um programa de defesa do hemisfério e, também, cooperação econômica. Tal contexto gerou uma aparente divisão nas Forças Armadas entre "entreguistas" e "nacionalistas". 6

Outro fator relevante é que os militares eram uma força social organizada nacionalmente e com acesso direto ao aparelho do Estado controlando os meios de coerção legal. Poderiam, portanto, garantir a ordem pública (tranqüilidade social, disciplina militar) e a ordem política (manutenção do regime, do sistema, pelo combate à subversão), indispensáveis para a implementação de qualquer plano de desenvolvimento. Tais considerações indicam que a política de desenvolvimento não se estabeleceria sem 0 apoio militar.

A "ameaça comunista", a possibilidade de infiltração de "ideologias extremistas" foram mecanismos usados por JK para chamar a atenção dos EUA e dos dirigentes da América Latina, inclusive das Forças Armadas brasileiras (instituição predominantemente anticomunista) para a questão do subdesenvolvimento. Assim, utilizando-se destes efeitos de sentidos, os caminhos do desenvolvimento se confundem com as estradas da segurança e da sobrevivência do país, isto é, o desenvolvimento passa a ser encarado como condição necessária para a segurança, já que zonas subdesenvolvidas são zonas potencialmente ocupadas pelo inimigo. As próprias palavras de JK no discurso às Forças Armadas confirmam como desenvolvimento e segurança se imbricam e como estas questões devem preocupar a todos e, consequientemente, ser do interesse de todos:

[...] Nações economicamente poderosas e subdesenvolvidas convivem no globo. Trata-se de um fenômeno que decorre de causas múltiplas e complexas, que demandam análise cuidadosa. Quero apenas deixar assinalado um aspecto dos mais importantes e que muito deve preocupar-nos: para os países do Ocidente, a solução do problema do subdesenvolvimento interessa vitalmente à segurança coletiva.

6 De acordo com BenEvides (id. ibid., p. 172-173), os "nacionalistas" (com maior presença no Exército) denominavam de "entreguistas" os militares que aderiam com mais facilidade à entrada do capital estrangeiro e não permitiam que alguns interesses se tornassem negociáveis, como, por exemplo, a Petrobrás e a presença de oficiais brasileiros em todos os setores de base ocupados pelos americanos. Mas, o nacionalismo mais exaltado em relação aos EUA acabava sendo "contido" pelo governo, pois, como os demais militares, os integrantes deste grupo também possuíam interesses relativos à cooperação técnica e financeira para maior produção de matérias-primas e equipamentos estratégicos, devendo o Brasil isentar de impostos os bens de importação e exportação ligados à "defesa comum". 
É, portanto, a partir dessas condições de produção que emerge o discurso de JK às Forças Armadas. A análise de discurso, como dispositivo teórico-metodológico, possibilita a apreensão dos sentidos dados por $\mathrm{JK}$ aos conceitos de segurança e de desenvolvimento. 0 discurso às Forças Armadas, compreendido como prática simbólica no conjunto das práticas sociais e na sua historicidade, passa a ser unidade textual, o material empírico que evoca interpretação e que pode ser definido pelo espaço de regularidades enunciativas pela sua inscrição histórica. Assim, o primeiro passo é desfazer as evidências contidas no discurso, é buscar compreender o seu funcionamento na materialidade lingüísticohistórica e nas condições de produção, possibilitando a apreensão dos efeitos ideológicos que cercam o par desenvolvimento/segurança.

Em todo discurso há uma ligação entre língua, históriae ideologia. A necessidade de se compreender a linguagem como uma formação socioideológica indica que o discurso é construído socialmentee que a ideologia, função necessária entre linguagem e mundo, naturaliza o que é produzido pela história através de efeitos de evidência que apagam a materialidade do discurso e constroem transparências, como se a linguagem e a história não tivessem sua espessura, sua opacidade. JK, ao iniciar sua fala às Forças Armadas, diz que "... parece oportuno dar-vos conhecimento pleno da obra continental que estamos encetando, no sentido de fazer confluírem as energias da América para uma revitalização do pan-americanismo, em face das exigências da presente conjuntura mundial".

Aqui, JK produz efeitos de sentidos que procuram persuadir as Forças Armadas sobre a necessidade de não se limitar aos objetivos próprios de defesa do país, confirmando a ampliação do conceito de segurança. Para a análise de discurso, no político o sentido é sempre dividido, tendo uma direção que se especifica na história, pelo mecanismo ideológico de sua constituição. Aí se ligam as noções do político, do histórico e do ideológico, explicitando que, ao significar, o sujeito se significa, e que o gesto de interpretação - perceptível ou não para o sujeito e/ou para os seus interlocutores determina a direção dos sentidos.

$\mathrm{JK}$, como sujeito do discurso, antecipa-se aos seus interlocutores quanto ao sentido que suas palavras produzem no que se trata do perigo que o regime democrático corre e afirma que "...A Anidade de ação política, em conjugação com o mais cuidadoso preparo da defesa militar, constituem fatores imprescindíveis, mas não bastam para eliminar o perigo". Ao produzir esses sentidos, silencia que este é um assunto da esfera política e deixa transparecer que o desenvolvimento é problema de segurança, portanto, é racional que todos o promovam. 
Segundo Pêcheux, palavras, expressões, proposições, etc. mudam de sentido segundo as posições ocupadas por aqueles que as empregam, o que quer dizer que elas adquirem seu sentido em referência às formações ideológicas nas quais essas posições se inscrevem, ou seja, a posição que o sujeito ocupa na hierarquia sócio-política dá força e legitimidade à sua fala.? Assim, ao expressar as exigências da presente conjuntura mundial, JK se utiliza de um discurso polissêmico, do qual fazem parte tanto os problemas internos como os externos. 0 sujeito - que no caso é o Presidente do país -, ocupa o mais alto grau na hierarquia institucional e traduz as relações de poder, provocando efeitos de sentidos convincentes quanto às suas concepções sobre o desenvolvimento e a segurança.

E mais, há a necessidade do Presidenteem tornar conhecida para as Forças Armadas a obracontinental (OPA) que estáencetando. 0 mundo aindaestá conturbado pelo pós-guerra, encontra-se sob o signo do gigantesco conflito ideológico, político e econômico, portanto, é necessário que a instituição (Forças Armadas) atente para uma revitalização do panamericanismo, para ofato de que o sentimento deve ser de umnacionalismo internacionalista que garanta a ordem, impedindo o surgimento e a infiltração de idéias subversivas, ou seja, 0 sentimento deve ser de um nacionalismo anticomunista. De acordo com Cardoso, este sentimento envolve o modo de vida, as crenças cristãse as instituições democráticas. ${ }^{8}$ As ideologias opostas são uma ofensa a todos esses elementos, portanto, se a fundamentação do esforço para o desenvolvimento éa segurança, cabe às Forças Armadas, como uma instituição do aparelho estatal, defender não somente a pátria, mas todo o Ocidente destas ofensas.

Ao se dirigir às Forças Armadas, sabe-se que JK lida com um Aparelho que tem por objetivo primeiro a Repressão, mas que também é ideológico e que, ao modo de Althusser, reproduz a ideologia "recrutando" sujeitos, levando-os a receber como evidente o sentido do que ouvem edizem, lêem ou escrevem. ${ }^{9}$ As Forças Armadas, nas próprias palavras deJK, constituem o cimento da unidade nacional e o seu esforço

dirige-se, também, aos estudos dos nossos grandes problemas e à valorização do homem brasileiro, mercê de uma ação formadora e educativa que se difunde proveitosamente por todo o nosso território [...] No desenvolvimento dos temas ligados à Operação Pan-Americana, como em todos os assuntos que interessem à segurança nacional, dispondo da valiosa contribuição das Forças Armadas, através de seus órgãos especializados.

7 Pêcheux, M. Semântica e discurso: uma crítica à afirmação do óbvio. Campinas: Editora da Unicamp, 1995. p, 161.

8 Cardoso, M. L. Ideologia do desenvolvimento - Brasil: JKJQ. Rio de Janeiro: Paz e Terra. 1978. p. 259.

9 AtTHusser, L. Aparelhos Ideológicos de Estado. Rio de Janeiro: Graal, 1983. pp. 70-5. 
Desenvolvimento como base para a segurança Ocidental é o slogan que cabia muito bem no projeto de JKe que necessitava ser legitimado. Os argumentos para legitimar são eloquientes: desenvolvimento, porque pobreza gera subversão. Porém, a pobreza é um estágio, um retardamento na longa rota do desenvolvimento que pode ser superado, mas para isso estamos todos convictos da necessidade da urgência de detido exame da conjuntura Pan-Americana, pois sozinhos não há como superar o subdesenvolvimento; $\mathrm{e}$ segurança, porque em nações desenvolvidas não se infiltram ideologias extremistas. A pobreza é potencialmente geradora de intranqüilidade, de revolta. Para manter a ordem Ocidental é preciso elevar o nível de vida do povo dos países subdesenvolvidos, pois, com os focos de insatisfação eliminados, não há perigo de que a inquietação passe para o plano político. Neste sentido, a ordem fica assegurada.

Esta é uma das faces deste discurso polissêmico. A outra é o fato do Presidente indicar a necessidade da manutenção das boas relações com a superpotência, mais um dos objetivos da OPA. Ao dramatizar o perigo comunista na América Latina e o poder soviético no mundo, JK estava preparando um futuro pleno de sentidos, estava procurando dar unidade e coerência a um discurso que era parte da formação discursiva ${ }^{10}$ dominante do período. JK deixa implícito neste momento que cabe também às Forças Armadas a tarefa de manter as boas relações com os EUA uma vez que, para despertar a confiança dos possíveis investidores e financiadores, era indispensável manter a ordem pública e a ordem política. Mas, as boas relações com a superpotência estão estremecidas por causa de

... certos fatos recentes, que vieram pôr à mostra um elo vulnerável na cadeia ocidental e patentearam a necessidade de que algo se faça para reforçar a nossa capacidade de resistência. Tais fatos tiveram lugar em nosso próprio continente. Constituíram a eclosão de um latente estado de coisas. Foram sintomas, signos aparentes de uma situação larvada. Ninguém ignora as manifestações agressivas de que foi alvo um estadista do nosso hemisfério em visita a países sul-americanos amigos. Ninguém ignora que esses incidentes foram provocados e canalizados por uma minoria interessada em fomentar discórdias na família continental.

Como jáfoi dito, foi a visita do vice-presidente dos EUA, Richard Nixon, que fez surgir a idéia de uma revisão do pan-americanismo. 0 episódio constituiu um evento traumático

${ }^{10}$ Essa é uma expressão utilizada por Michel Foucault para designar um conjunto de enunciados marcados pelas mesmas regularidades, pelas mesmas "regras de formação". Este autor foi de grande importância para as pesquisas lingüísticas, pois definiu o que vem a ser discurso, formação discursiva, enunciado, enunciação conceitos fundamentais para a análise de discurso. 
quepossibilitava a alteração do padrão vigentedas relações interamericanas. Nixon foi insultado no Peru eatacado na Venezuela por uma multidão furiosa. Eisenhower mobilizou tropas para um eventual desembarque e resgate de Nixon em Caracas, gerando uma onda de protestos políicos em todo o continente. 0 evento acentuou a distância entre EUAe a América Latinae realçou a dicotomia do discurso de seus respectivos grupos dirigentes: os latino-americanos falando a linguagem do desenvolvimento econômico, e os norte-americanos apegados ao discurso dasegurança. Portanto, a 0 PA era uma formade resgatar o fortalecimento das relações interamericanas eassociar desenvolvimento esegurança.

De início, foi tímida a receptividade de Washington à idéia lançada por JK - na verdade por Augusto Frederico Schmidt, ${ }^{11}$ assessor especial de $\mathrm{K}$-, mas isso não desanimou o Presidente, pois logo depois ele conseguiu que a embaixada em Washington produzisse um plano geral da OPA e fez com que Eisenhower verificasse que ele recebia apoios na região e se constituía em núcleo político com potencial de aglutinação. Assim, em nome da segurança ocidental JK passa a deslocar elementos da esfera econômica para a esfera política e, como detentor do mais alto grau político do país, dissemina essas idéias. Os efeitos de sentidos contidos aparecem como uma verdade que faz com que o lugar a partir do qual o sujeito fala se torne constitutivo do que diz. Quem está falando éo Presidente, sua fala funcionapara assegurar permanência de representações, imagens que se sustentam no poder e que se fazem valer no dizer.

É preciso que nos compenetremos da idéia de que a luta contra o subdesenvolvimento na América Latina importa em promover a segurança do continente e, nessas condições, deve inserir-se no programa estratégico da defesa ocidental. Algo de concreto e positivo deve ser feito para minorar os sofrimentos de milhões de homens, para elevar o nível de vida de nossas populações e facultar ao maior número 0 acesso a uma existência material condigna, sem a qual ninguém encontrará alento para dedicar-se de corpo e alma às grandes causas morais e espirituais. 0 necessitado e 0 abandonado não podem resignar-se à injustiça de sua sorte, nem ligar-se fraternalmente ao que vive na fartura. As excessivas desigualdades econômicas são geradoras de ressentimento e inquietação. Incontentadas, as massas procuram

$"$ Augusto Frederico Schmidt foi o mentor da OPA, porém JK, ao se dirigir às Forças Armadas, não menciona Schmidt e se coloca na origem do que diz. Para $\mathrm{AD}$, esse é o esquecimento ideológico, éda instância do inconsciente e resulta do modo pelo qual somos afetados pela ideologia. Este esquecimento reflete o sonho adâmico, isto é, o de estar na inicial absoluta da linguagem, dizendo as primeiras palavras que significariam exatamente o que queremos. As primeiras idéias de Schmidt sobra a OPA podem se encontradas na obra de CERvo, A. \& BuENo, C. História da politica exterior do Brasil. Brasilia: Editora da UnB, 2002. p. 261 ou ainda na de Peixoro, A. Artes da Política. Rio de Janeiro: Nova Fronteira/CPDoc - Fundação Getúlio Vargas, 1986. p. 414. 
explicação para seus males em raciocínios simplistas e tornam-se receptivas às propagandas ilusórias. A existência do subdesenvolvimento equivale à 'própria presença do adversário em nossa casa'. Não podemos por mais tempo permitir que se instale esse inimigo, sob pena de conseqüências irremediáveis.

Estes dizeres produzem efeitos de sentidos que explicitam como linguagem e ideologiase articulam. A forma utilizada serve para integrar uma sociedade e sua história, particularmente à do subdesenvolvimento que assola a América Latina. Ao apontar o anticomunismo, JK demonstra como o modo de dizer nunca é indiferente aos sentidos. Utilizando-se do silêncio, da paráfrase, da metáfora, da polissemia, ele não usa o termo comunismo, ou o silencia ou o trata como oligarquias, como adversários, inimigos e também como uma ideologia que pretende o enfraquecimento dos organismos nacionais através de uma infiltração lenta e persistente em nações cujas populações estão sob o espectro da fome e da miséria.

Afala de JK também se remete, em termos gerais, "à valorização do homem", ou seja, ele crê que com o desenvolvimento virá a prosperidade e que ela não atingirá apenas grupos particulares, mas a sociedade inteira. Porém, a própria formulação de seu discurso, os objetivos da OPA, o plano de desenvolvimento, etc., confirmam que a finalidade do governo de JK, em termos objetivos, é eminentemente econômica. Ora, ao se desenvolver um plano de desenvolvimento econômico necessita-se de recursos. Manter boas relações com os EUA era essencial e despertar confiança também, mas depois disso, o mais indispensável era fazê-los associar subdesenvolvimento e subversão e levá-los a acreditar que o regime democrático só vigora em países que se afirmam economicamente. ${ }^{12}$

Essas enunciações que articulam a pobreza, a miséria, o subdesenvolvimento às manifestações ocorridas na América Latina eram mecanismos utilizados por JK para que os EUA assumissem um compromisso político com a erradicação do subdesenvolvimento latino-americano, compromisso político que incluiria a alocação de investimentos públicos. Ao englobar a defesa do Ocidente, da democracia e, consequientemente, do capitalismo, JK se inseria numa formação discursiva que corresponderia aos próprios interesses americanos, ou seja, a estabilidade política do continente.

A população se manifestou contra Nixon para que os EUA assumissem algum tipo de acordo que implicassecapitais destinados a amenizar suas mazelas e acelerar seu desenvolvimento econômico, mesmo porque Washington insistia que o desenvolvimento latino-americano era

${ }^{12}$ Sobre a política econômica brasileira e a relevância da conjuntura internacional no período ver LEopoLDI, M.A.P. Crescendo em meio à incerteza: a política econômica do governo JK (1956-60). In: O Brasil de JK. Op. cit. p. 109-111. 
um problema interno ao continente, que deveria ser resolvido através da adoção de políticas econômicas "responsáveis" e da criação de um ambiente favorável ao investimento privado, nacional eestrangeiro; os recursos públicos dos EUA continuariam assim concentrados naquelas regiões do mundo que eram vistas como prioritárias dentro da competição global da Guerra Fria: primeiro a Europa, eposteriormente a Ásia. Como pode ser constatado, KK se beneficiou da fortuna. ${ }^{13}$ Washington via as "massas incontentadas" da América Latina como um perigo de subversão àsegurançado Ocidente. Este contexto serviu paraJK dizer que ideologias extremistas poderiam se infiltrar nas mentes da população pobre daAmérica Latina naquele período.

Naperspectiva oferecida por Bourdieu ${ }^{14}$, no campo político existem mecanismos sociais que produzem e reproduzem aseparação entre os "agentes politicamente ativos" eos "agentes politicamente passivos". 0 capital político ${ }^{15}$ acaba se concentrando nas mãos de um pequeno grupo; o restante dos cidadãoséreduzido ao estatuto de "consumidores" eenfrentam dificuldades para acessar o campo de ação, que exige competência social para a política e instrumentos próprios de produção de discursos ou atos políticos. Quando o acesso ao campo de ação ocorre, resta às massas, muitas vezes, o papel de coadjuvante.

É neste sentido que a análise do discurso permite-nos refletir que o discurso é prática. As formações discursivas representam no discurso as formações ideológicas. Entretanto, tal prática discursiva não é o reflexo da situação nem está mecanicamente determinada por ela. Um acontecimento, como as manifestações contra Nixon, por exemplo, é cercado pelos sentidos ordinários da vida cotidiana e por mais que esse acontecimento possa parecer perfeitamente transparente, mostra-se profundamente opaco, pois, no jogo político há um universo de coisas que não podem ser ditas, portanto, parase compreender o discurso político épreciso analisar todo o processo de produção ideológica.

Silenciar também que um dos objetivos da OPAé captar recursos para desenvolver a América Latina faz parte do jogo político de JK. Mas o diagnóstico do subdesenvolvimento elaborado por umacomissão do Itamaraty, com basenum círculo vicioso deescassezdepoupança - falta de investimentos - e baixa produtividade, fatores encarados ao mesmo tempo como causa e efeito do mal maior que se pretendia combater, previa o aporte de US $\$ 3,1$ bilhões até 1967 , com juros fixos de $4,25 \%$ ao ano apenas para o desenvolvimento do Brasil.

Washington evitava se comprometer concretamente com a definição do montante

${ }^{13}$ Fortuna é um termo utilizado por Maquiavel, e que designa a oportunidade criada pela sociedade para se fazer a história. Porém, se houver apenas a fortuna sem virtù (capacidade) ou vice-versa, a história não se faz.

14 Bourdieu, P. O poder simbólico. Trad. Fernando Tomaz. Rio de Janeiro: Bertrand Brasil, 2001. pp. 164-175.

15 Segundo Bourdiru (id. ibid.), possui capital político aqueles que se apossam de instrumentos materiais e culturais necessários à participação ativa na política. 0 capital econômico e o cultural servem de exemplo de instrumentos materiais. 
de recursos e tinha a seu favor a inexistência de projetos nacionais integrados de desenvolvimento econômico na América Latina que pudessem ser postos em prática de forma imediata. Também favorecia a resistência norte-americana à OPA uma certa intensificação e até uma duplicidade tática do governo brasileiro, resultante da dicotomia entre a condução propriamente diplomática (Itamaraty) e a condução política (Catete) das iniciativas brasileiras. Assim, dramatizar o perigo comunista na América Latina e o poder soviético no mundo, serviu como alavanca para abrir os cofres norte-americanos.

Nossos referenciais teóricos permitem-nos considerar que o discurso de $\mathrm{K}$, no que se refere ao perigo comunista, foi um efeito de sentido regido pelo imaginário. Mas, o equívoco, afalha, a contradição, constitutivos tanto do discurso como do sujeito, acabaram se insinuando, provocandodeterminada desconfiança por parte dos diretamente envolvidos. Isso explicaporque as Forças Armadas deviam estar a par da OPA. Fazer convergir os interesses do governo e os dos militares era mais uma das estratégias de JK, devido à importância desta instituição para alcançar a realização do projeto desenvolvimentista. Assim, as palavras deJK expressam que as providências em relação à OPA estavam sendo tomadas de forma adequada, mas ficariam melhor com o apoio esugestões das Forças Armadas, que podiam auxiliar a preparar melhor o terrenopara o alcance do objetivo comum.

No Brasil, os diplomatas, os técnicos e os estudiosos já se dedicam ao grande problema, em todos os seus aspectos, para que possamos, em tempo oportuno, exprimir pontos-de-vista e apresentar sugestões. No desenvolvimento dos temas ligados à Operação Pan-Americana, como em todos os assuntos que interessem à segurança nacional, dispondo da valiosa contribuição das Forças Armadas, através de seus órgãos especializados.

Considerando as condições de produção do discurso deJK apresentadas atéo momento, já não se pode deixar de constatar que elas implicam o que é material (a língua sujeita ao equívoco e à historicidade), o queé institucional e 0 mecanismo imaginário. ${ }^{16}$

As Forças Armadas, que possuíam como "fiador do regime" o general Lott, eram

${ }^{16}$ Por esse ângulo de análise de discurso, existe uma relação necessária e sempre presente entre o real e o imaginário, e é por essa articulação que o discurso funciona. Portanto, sujeito e autor, discurso e texto devem ser distinguidos ao se fazer uma análise de discurso. Como o lugar da unidade é o texto, o sujeito se constitui como autor ao constituir o texto em sua unidade, com sua coerência e completude. A unidade está na instância do imaginário enquanto o que se tem de real no discurso é a dispersão, a incompletude, o equívoco. Assim, um discurso pode ser afetado por distintas formações discursivas, diferentes posições do sujeito, mas como ele é sempre regido pela força do imaginário da unidade, se estabelece uma relação de dominância de uma formação discursiva com as outras na sua constituição. É esse efeito discursivo regido pelo imaginário que dá uma direção ideológica ao discurso. 
sem dúvida relevantes para a estabilidade do governo sem, contudo, abalar de maneira irreversível os alicerces do poder civil. Também tinham interesse em apoiar a política econômica do governo e tornaram-se co-responsáveis pelo programa de desenvolvimento, ${ }^{17}$ mas para apoiarem, foram cooptadas para os cargos executivos na administração pública e para os setores mais importantes da economia nacional, ou seja, para apoiarem, se beneficiaram do poder que lhes foi concedido. De qualquer forma, é importante destacar que a instituição militar foi um aparelho de Estado extremamente relevante no período e que o esquema montado, tanto no que diz respeito à ideologia (desenvolvimentista) como no que se refere aos interesses econômicos, confirma como o Presidente soube jogar com 0 aparelho estatal como um todo. ${ }^{18}$

Porém, mesmo reconhecendo a importância dos investimentos estrangeiros para a superação do subdesenvolvimento, havia a questão da soberania. 0 Brasil tinha que estar em condições de falar de igual para igual, sem nenhuma subserviência, sem nenhum receio, sem nenhum sentimento de inferioridade em relação à superpotência. Assim, 0 discurso de JK às Forças Armadas não trata de dependência, mas sim de interdependência. É interessante observar que o termo soberania no discurso para as Forças Armadas, cuja conotação se relacionava à defesa nacional, podia ser explorado. Já nas falas dirigidas aos possíveis investidores, a probabilidade de aparecer o termo era muito menor, uma vez que ele funcionava mais positivamente quanto menos estivesse presente. 0 enunciado abaixo demonstra como JK se dirigia às Forças Armadas quando o assunto era soberania:

Nossa união no plano espiritual e político é reforçada pelos laços de natureza econômica. Temos, nos Estados Unidos, o nosso maior cliente, o escoadouro natural para a boa parte de nossa exportação, o grande mercado para os nossos produtos básicos. 0 vínculo não é de subordinação, mas de interdependência. Oscilações acentuadas na procura ou nos preços dos nossos principais produtos no mercado norte-americano têm reflexo imediato e desastroso sobre a economia brasileira. Os Estados Unidos, por seu lado, não podem prescindir daqueles produtos, como 0 demonstrou a experiência do último conflito mundial, quando se tornou necessário um planejamento de emergência para assegurar aos nossos aliados o prosseguimento e intensificação das exportações brasileiras.

A concepção de dependência existente na teoria de Cardoso e Faletto não é

\footnotetext{
${ }^{17}$ Para uma compreensão ampla do programa de desenvolvimento de JK ver LAFER, C. JK e o programa de metas (1956-1961): processo de planejamento e sistema político no Brasil. Rio de Janeiro: Editora FGV, 2002.

${ }^{18}$ BENEVIDES, M.V. 0 governo Kubitschek: a esperança como fator de desenvolvimento. In: O Brasil de JK Op. cit., pp. 32-3.
} 
compatível com a idéia de JK quanto à possibilidade de um vínculo sem subordinação. ${ }^{19}$ Eles até destacam que épossível substituir a idéia de dependência pela de interdependência, porém, consideram que a inserção subordinada da sociedade nacional no sistema capitalista internacional já é algo de bom tamanho para o desenvolvimento brasileiro; que as relações entre o interno e o externo são relações de interdependência, pois, nessa fase do capitalismo os países centrais não mais se opõem, como antes, à industrialização e ao crescimento dos países dependentes. E mais, a superação ou manutenção das barreiras estruturais ao desenvolvimento e a dependência subordinam-se, mais a condições econômicas tomadas isoladamente, que à ação coletiva motivada por vontades políticas que tornem factível o que estruturalmente é apenas possível.

Mas, é necessário pensar que, geralmente, por trás das vontades políticas sempre há interesses singulares. O maior desejo de JK era realmente o desenvolvimento econômico, a prosperidade, cujo resultado seria o bem estar material da população. Contudo, outros interesses ${ }^{20}$ também faziam parte do jogo político, como, por exemplo, a tentativa de transformar o Brasil em condutor do desenvolvimento na América Latina. Assim, as boas relações com a superpotência, a tentativa de captar recursos e a de tornar o Brasil líder do desenvolvimento eram objetivos da OPA que caminhavam juntos. Se qualquer um deles não se concretizasse, o plano ficaria comprometido, mas se tudo se encaminhasse, o capital simbólico que o Brasil e, particularmente JK, iriam acumular, teria repercussões por todo o Ocidente.

Portanto, definir aquilo que pode e deve ser dito é uma estratégia do jogo político. As palavras, expressões, proposições, recebem seu sentido da formação discursiva na qual são produzidas; as proibições não funcionam como elementos a serem afastados, mas sim formando o discurso para que ele possa funcionar otimamente. E mais, a escolha de um tema não provém apenas de uma visão de um sujeito, assim, como os conceitos não provêm necessariamente de idéias inerentes somente ao sujeito, e sim dos elementos que uma dada formação discursiva provoca.

Tornar o Brasil líder da América Latina e captar recursos para colocar em prática

19 Cardoso; Faletro. Dependência e desenvolvimento na América Latina. Rio de Janeiro: Editora LTC, 1970. p. 142.

${ }^{20}$ Segundo Bourdieu (op. cit. p. 168), os dirigentes possuem o monopólio dos instrumentos de produção dos interesses políticos. Isso faz com que nada prove que os interesses dos mandatários coincidam com os interesses dos mandantes. Mas a ideologia cumpre aqui a sua função. A OPA aparecia como sendo planejada democraticamente, quando sabemos que, na verdade, o planejamento se dava no nível das instituições, consideradas pelo autor como unidades de produção controladas por profissionais que detém o monopólio do discurso e da ação política. 
o Plano de Metas visando eleições futuras faziam parte daquilo que não podia ser dito no discurso político deJK. Mas, através de um discurso que não era puro nem neutro, elepôde explorar o acontecimento, ou seja, a Guerra Fria, adaptando-o a estes interesses. ${ }^{21}$

Os resultados diretos de tal contexto foram que, ao associar segurança e desenvolvimento,JK conseguiu, através da OPA, que se formasse dentro das Organizações dos Estados Americanos/OEA um Comitê das 21 Repúblicas Americanas - o chamado Comitê dos 21 -, incumbido de estudar os principais "pontos de estrangulamento" das economias latino-americanas e formular novas medidas de cooperação econômica interamericana.

Mesmo quando JK rompeu com o FMI, em 1960, por causa do aumento da inflação que a construção de Braslia gerava, contradizendo a política de austeridade fiscal, Eisenhower veio ao Brasil buscar diálogo, demonstrando que as relações exteriores do paíse, principalmente comosEUA agoraeram tratadas num plano multilateral - o Comitêdos 21-, que buscavadar voz às aspirações coletivas dos países latino-americanos, com base na temática comum do subdesenvolvimento. Além disso, a OPA também representou abusca de uma política externa mais autônoma em relação às diretrizes emanadas de Washington, apontando para um tríplice alargamento de horizontes que seria retomado a seguir pela diplomacia brasileira: multilateralismo, desenvolvimento, autonomia.

A OPA atingiu seu ponto máximo na política externa com a eclosão da Revolução Cubana e, a partir de 1960, e especialmente na gestão de Kennedy, na qual se operaria plenamente uma revisão radical de sua política de "negligência benigna" em relação à América Latina. ${ }^{22}$ Os resultados não foram melhores porque a ausência de uma articulação prévia com os países vizinhos, transformou a 0 PA mais em uma declaração de intenção ou um desejo genérico de mudanças do que propriamente uma iniciativa política com suficiente capacidade de pressão.

0 discurso às Forças Armadas significou a busca de manutenção do apoio desta

${ }^{21}$ Vários autores indicam que a política de JK sempre visava eleições futuras. Como exemplos, podem ser citados Bojunga, C. $O$ artista do impossivel. Rio de Janeiro: Objetiva, 2001 e Maran, Sheldon. Juscelino e a política presidencial. In: O Brasil de JK.Op. cit. pp. 144-169.

22 "Negligência benigna" designa a política adotada pelos EUA em relação ao desenvolvimento econômico da América Latina, isto é., significa que a América Latina ocupava baixo lugar na escala de prioridades na política externa global dos EUA. Como já foi mencionado, os EUA consideravam o problema do desenvolvimento latino-americano como um problema que deveria ser resolvido por meio de políticas econômicas "responsáveis" e da criação de um ambiente favorável ao investimento privado, nacional e estrangeiro. Segundo SILva, A.M. A política externa brasileira no cenário da Guerra Fria. In: Os anos de JK. Site do CpDochttp://www.cpdoc.fgv.br/ ,2002. p. 3, a revisão radical da política de "negligência benigna", preconizava medidas detalhadas e concretas de desenvolvimento econômico e social . 
instituição que foi cortejada por JK desde o início de sua gestão. A linguagem utilizada por ele quando se dirigia aos militares era sempre uma linguagem nacionalista, com a qual a maioria dos oficiais podia concordar. Para tranquilizar os anticomunistas, as suas declarações sempre realçavam a ordem vigente (democracia) e não possuíam elementos antiamericanistas, nem ataques ao "imperialismo". Nesse sentido, se no discurso se define o que pode ser dito, neste caso, o não-dito é que prevalece. Silenciar elementos antiamericanistas, não atacar o imperialismo, foi um recurso ideológico, uma estratégia discursiva utilizada por JK para enfatizar que o "interesse entre Brasil e EUA é mútuo e que, quando houver desacordo, devemos apresentar as razões de nosso desacordo; ou de nosso aplauso à conduta norte-americana na causa que é igualmente nossa".

A sedução dos militares indica que, para JK, a manutenção da ordem era tão importante quanto a defesa das liberdades políticas. Apesar de ter ocultado as crises, o próprio JK destacava que o seu governo se assentava num tripé. Esse tripé era formado pelo conjunto das Forças Armadas, responsável pela estabilidade do regime num momento em que o sistema político era estável no jogo das forças políticas, porém instável do ponto de vista institucional. Foi esta uma das causas que levou JK a permitir a crescente "tutela militar". 0 comprometimento prioritário do governo com o desenvolvimentismo trazia a ordem como premissa básica para sua concretização, cuja ideologia empreendia "mudar, dentro da ordem, para garantir a ordem", o que significava manter o regime vigente, isto é, consolidar a segurança do sistema.

Enfim, o caráter ideológico que carregava o discurso de JK alterou o legalismo militar - por influências externas emface dos rumos socializantes da revolução cubana-, mas também pela efervescência da política interna. 0 que antes significava um legalismo constitucional militar, de respeito à Constituição e de subordinação à lei, passou a ser um legalismo condicionado a uma atitude basicamente anticomunista e que considerava "subversiva" toda e qualquer manifestação popular.

Portanto, pode-se compreender a importância do papel da ideologia, ou melhor, pode-se compreender que os sentidos são sempre determinados ideologicamente, tudo que é dito tem um traço ideológico em relação a outros traços ideológicos, e isto não está na essência das palavras, mas na discursividade, na maneira como, no discurso, a ideologia produz seus efeitos, materializando-se nele. Os efeitos de sentidos contidos no discurso de JK fazem com que 0 aspecto econômico, na verdade, o básico da ideologia desenvolvimentista, perca a ênfase, enquanto os aspectos politizantes, que envolvem a segurança e passam a dar sentido ao desenvolvimento, aparecem em nível ideológico e coerente, indicando que aquilo que está sendo dito reflete "verdadeiramente" a situação. 
As palavras finais do discurso de JK às Forças Armadas demonstram bem como a ideologia desenvolvimentista articula o real e o imaginário. Antecipando-se aos seus interlocutores, dirige o processo de argumentação visando seus efeitos e produz uma ilusão referencial sobre a urgência da superação do subdesenvolvimento não apenas para o Ocidente, mas agora para toda a humanidade.

A Operação Pan-Americana é mais do que palavra oportuna e certa, é um caminho. A tese de que a luta contra o subdesenvolvimento é uma medida estratégica indispensável, de capital importância, tornou-se clara, evidente, inegável. Não há outro caminho a seguir senão a união continental para fortificação desta parte do mundo livre. Não podem as forças da democracia se apresentar ao mundo para propor uma fórmula seja lá qual for, quando no reduto mais importante da resistência democrática se apresentam índices tão impressionantes de subdesenvolvimento. Nossa tese tornou-se indiscutivel, mais atual do que nunca, e será temerário não a transformar numa política segura e certa.

Recebido em setembro de 2004. 